homology. The last of the human sequences differed at 2 positions owing to mixed bases. The chromatogram showed equal intensities at both positions $\mathrm{C}$ and $\mathrm{T}$ (Figure, http://wwwnc.cdc.gov/EID/article/22/11/16-1171-F1. $\mathrm{htm})$. This finding indicates that quasispecies might be present. These positions in the human sequence coincided perfectly with 2 of the 3 positions found to vary in the sequence obtained from oyster sample D. All 3 base variations were a replacement of a $\mathrm{C}$ with a $\mathrm{T}$ (Figure), which further supports the presence of quasispecies. However, in this setup, it was not possible to prove the origin of these closely related species. Whole-genome sequencing using next-generation sequencing would be a way to prove the simultaneous presence of all quasispecies in relevant samples.

Since the emerging of GII.P17-GII.17 in Asia, sporadic cases have been reported worldwide $(3,9)$. In this study, we established a direct molecular link between a common food source and a series of acute gastroenteritis outbreaks. Even though these represent European outbreaks, our results show that oysters act as vehicles for the rapid spread of emerging noroviruses to distant geographic areas. Furthermore, we document that quasispecies of GII.P17-GII.17 might occur simultaneously in a host. This finding should be considered in future molecularepidemiologic outbreak investigations.

\section{Acknowledgments}

We thank Joanna Zeitman Amenuvor and Resadije Idrizi for excellent technical assistance.

The study of the oysters was partially funded by Aquavalens (EU FP7-KBBE-2012-6) (http://aquavalens.org/).

Dr. Rasmussen is a molecular biologist working as a senior scientist at Statens Serum Institut. His primary research interest is emerging viruses.

\section{References}

1. Atmar RL, Estes MK. The epidemiologic and clinical importance of norovirus infection. Gastroenterol Clin North Am. 2006;35:27590, viii. http://dx.doi.org/10.1016/j.gtc.2006.03.001

2. Lu J, Fang L, Zheng H, Lao J, Yang F, Sun L, et al. The evolution and transmission of epidemic GII.17 noroviruses. J Infect Dis. 2016;214:556-64. http://dx.doi.org/10.1093/infdis/jiw208

3. de Graaf M, van Beek J, Vennema H, Podkolzin AT, Hewitt J, Bucardo F, et al. Emergence of a novel GII.17 norovirusend of the GII.4 era? Euro Surveill. 2015;20:21178. http://dx.doi.org/10.2807/1560-7917.ES2015.20.26.21178

4. Franck KT, Fonager J, Ersbøll AK, Böttiger B. Norovirus epidemiology in community and health care settings and association with patient age, Denmark. Emerg Infect Dis. 2014; 20:1123-31. http://dx.doi.org/10.3201/eid2007.130781

5. Kroneman A, Vennema H, Deforche K, van der Avoort H, Peñaranda S, Oberste MS, et al. An automated genotyping tool for enteroviruses and noroviruses. J Clin Virol. 2011;51:121-5. http://dx.doi.org/10.1016/j.jcv.2011.03.006

6. Dang Thanh H, Than VT, Nguyen TH, Lim I, Kim W. Emergence of norovirus GII.17 variants among children with acute gastroenteritis in South Korea. PLoS One. 2016;11:e0154284. http://dx.doi.org/10.1371/journal.pone.0154284

7. Franck KT, Lisby M, Fonager J, Schultz AC, Böttiger B, Villif A, et al. Sources of calicivirus contamination in foodborne outbreaks in Denmark, 2005-2011: the role of the asymptomatic food handler. J Infect Dis. 2015;211:563-70. http://dx.doi.org/10.1093/ infdis/jiu479

8. Müller L, Schultz AC, Fonager J, Jensen T, Lisby M, Hindsdal K, et al. Separate norovirus outbreaks linked to one source of imported frozen raspberries by molecular analysis, Denmark, 2010-2011. Epidemiol Infect. 2015;143:2299-307. http://dx.doi.org/10.1017/ S0950268814003409

9. de Graaf M, van Beek J, Koopmans MPG. Human norovirus transmission and evolution in a changing world. Nat Rev Microbiol. 2016;14:421-33. http://dx.doi.org/10.1038/nrmicro.2016.48

Address for correspondence: Lasse Dam Rasmussen, Afdeling for Mikrobiologisk Diagnostik og Virologi, Sektor for Diagnostik og Infektionskontrol, Artillerivej 5, DK-2300 Copenhagen S, Denmark; email: lara@ssi.dk

\title{
Recent Chikungunya Virus Infection in 2 Travelers Returning from Mogadishu, Somalia, to Italy, 2016
}

\section{Lorenzo Zammarchi, Claudia Fortuna, Giulietta Venturi, Francesca Rinaldi, Teresa Capobianco, Maria Elena Remoli, Gian Maria Rossolini, Giovanni Rezza, Alessandro Bartoloni}

Author affiliations: Università Degli Studi di Firenze, Florence, Italy (L. Zammarchi, F. Rinaldi, G.M. Rossolini, A. Bartoloni); Azienda Ospedaliero-Universitaria Careggi, Florence (L. Zammarchi, T. Capobianco, G.M. Rossolini, A. Bartoloni); Istituto Superiore di Sanità, Rome, Italy (C. Fortuna, G. Venturi, M.E. Remoli, G. Rezza); Università di Siena, Siena, Italy (G.M. Rossolini); Fondazione IRCCS Don Carlo Gnocchi, Florence (G.M. Rossolini)

\section{DOI: http://dx.doi.org/10.3201/eid2211.161225}

To the Editor: Since chikungunya virus (CHIKV) was first isolated in 1952 (in Tanzania), outbreaks have occurred every 7-20 years in countries in Africa and Asia, and since 2013, it has been identified in the Americas $(1,2)$. However, no cases have been reported from the Horn of Africa $(3,4)$. We confirmed CHIKV infection acquired in 2016 by 2 travelers to Somalia who returned to Italy.

In June 2016, a Somali woman (patient 1) was referred to the Infectious and Tropical Diseases Unit, Careggi University Hospital, in Florence, Italy, because of severe diffuse 
bilateral arthralgia and edema in hands, wrists, ankles, and feet. Five days earlier, she had returned to Italy from Mogadishu, Somalia, where she had spent 45 days visiting relatives. The woman had been living in Italy since the 1990s and returned to Somalia each year for $\approx 2$ months; she denied travel to other countries. She reported that symptoms started abruptly in May, 17 days after arriving in Somalia (28 days before returning to Italy). At symptom onset, arthralgia was associated with fever and skin rash, which lasted a few days.

In early July 2016, another Somali woman (patient 2) with bilateral arthralgia in her hands, wrists, ankles, and feet associated with foot edema sought medical care at the same hospital 7 days after returning from a 65-day trip to Mogadishu, where she visited relatives. The woman had been living in Italy $\approx 20$ years; the only other travel she reported was to Kenya in 2012. Her symptoms started in June, 20 days after arriving in Somalia (45 days before returning to Italy). At symptom onset, she also had skin rash and fever, which lasted a few days.

Both patients reported that, during the same period, some of their relatives in Mogadishu had similar symptoms and were clinically diagnosed as having chikungunya fever by local doctors. Both also reported that, during the same period, other cases had been reported in Mogadishu by mass and social media and, thus, the local population was aware of the disease.

Serum samples for patients 1 and 2 were positive for CHIKV antibodies (Table). Both patients were treated with nonsteroidal antiinflammatory drugs and corticosteroids and are receiving follow-up.

According to the US Centers for Disease Control and Prevention, as of April 22, 2016, CHIKV had not been reported from Somalia (4), and no evidence exists for CHIKV circulation in that area of the Horn of Africa (3). In addition, on August 3, 2016, we performed a literature search in PubMed, Embase, and ProMED-mail, and found no reports of CHIKV in Somalia. Poorly documented preliminary data on the presence of CHIKV in Somalia were recently reported in 2 documents by the United Nations Office for the Coordination of Humanitarian Affairs. One document, dated June 7, 2016, stated "There are reports of an outbreak of the deadly Chikungunya virus in Banadir Region. According to WHO [the World Health Organization], 3 of 5 blood samples have tested positive" (reference 1 in online Technical Appendix, http://wwwnc.cdc. gov/EID/article/22/11/16-1225-Techapp1.pdf). The second document, dated June 30, 2016, stated that "some 11 suspected cases of Chikungunya were confirmed... in Mogadishu" (reference 2 in online Technical Appendix). Several reports in the online press and social media have reported the current circulation of CHIKV in Somalia, including 2 Twitter posts (tweets) by the Ministry of Health of Kenya (references 3-7 in online Technical Appendix). A Somali doctor living in Italy obtained confirmation of CHIKV circulation in Somalia by contacting colleagues at the Ministry of Health in Mogadishu (Omar Abdulcadir, Careggi University Hospital, pers. comm., 2016 Jul 19).

Direct and indirect evidence exists for the presence of competent CHIKV vectors (e.g., Aedes aegypti mosquitoes) in Somalia. Entomologic studies conducted in 1942 and 1969 confirmed the presence of $A$. aegypti mosquitoes in several cities along Somalia's coast, including Mogadishu (5). Other arboviruses in which Aedes mosquitoes play a role as reservoir (Rift valley fever $[\mathrm{RVF}]$ ) and vector

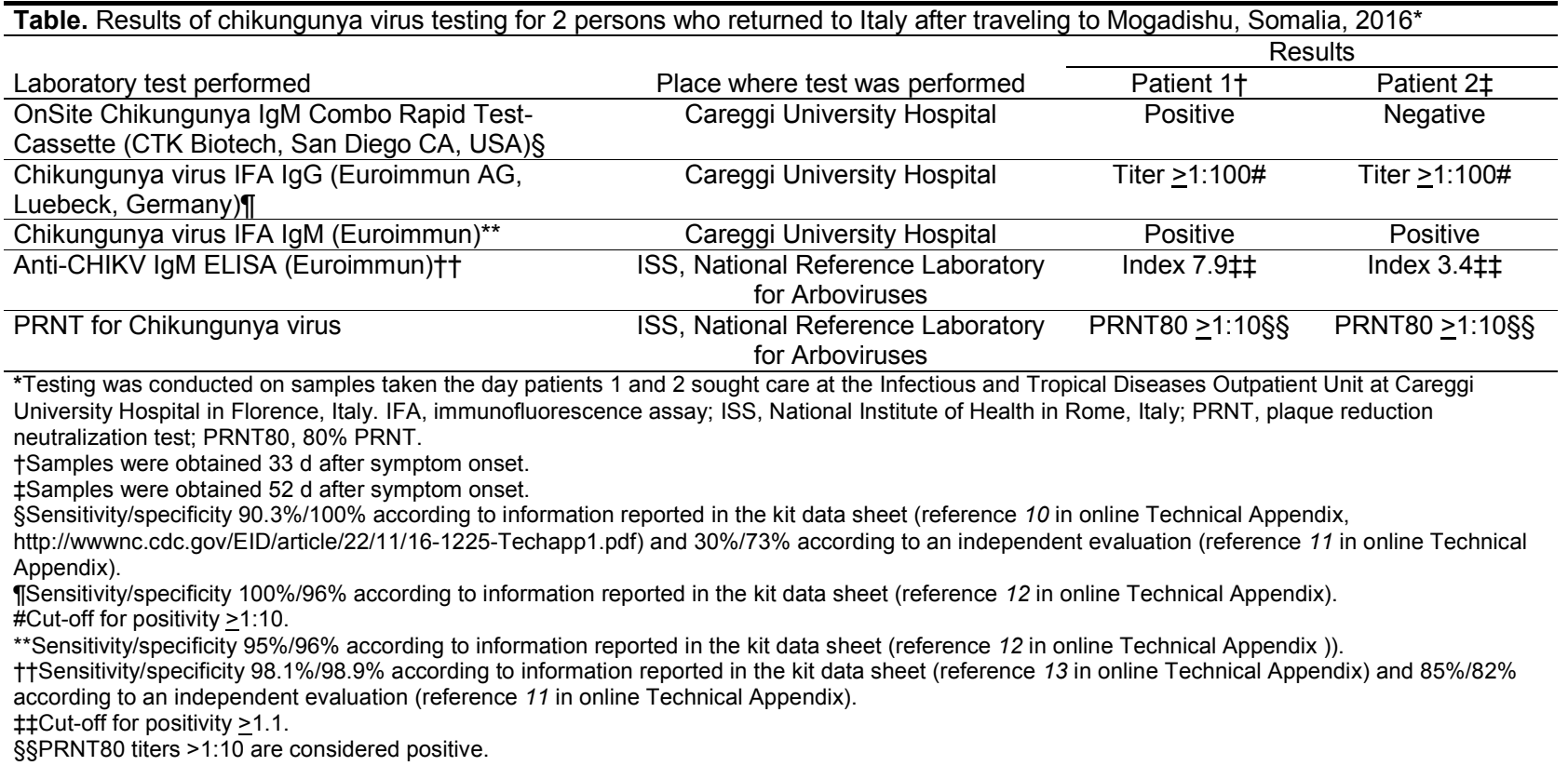


(dengue and possibly RVF) have been reported in recent years in Somalia: RVF outbreaks occurred during 1997 1998 and 2006-2007 (6,7), and a dengue outbreak occurred during 1992-1993 (8).

The current outbreak in Somalia could have been triggered by several factors, including circulation of CHIKV in neighboring Kenya (references 8,9 in online Technical Appendix) and heavy rains that led to flooding in southern and central Somalia beginning in January 2016 (reference 1 in online Technical Appendix). CHIKV has the potential to provoke explosive outbreaks in naive populations (9), so the current outbreak may greatly affect the economy and public health in Somalia.

Systematic studies to understand the magnitude of the ongoing epidemic are needed. In the meantime, local public health stakeholders in Somalia and healthcare workers worldwide caring for travelers returning from Somalia should be aware that CHIKV is circulating in the country. This report confirms the importance of travel medicine services in performing early diagnosis of imported arboviral diseases, not only to thwart secondary transmission during periods of competent vector activity but also to help to detect or confirm virus circulation in previously unaffected countries.

\section{References}

1. Madariaga M, Ticona E, Resurrecion C. Chikungunya: bending over the Americas and the rest of the world. Braz J Infect Dis. 2016;20:91-8. http://dx.doi.org/10.1016/j.bjid.2015.10.004

2. Magurano F, Zammarchi L, Baggieri M, Fortuna C, Farese A, Benedetti E, et al. Chikungunya from the Caribbean: the importance of appropriate laboratory tests to confirm the diagnosis. Vector Borne Zoonotic Dis. 2015;15:258-60. http://dx.doi.org/10.1089/vbz.2014.1724

3. Nsoesie EO, Kraemer MU, Golding N, Pigott DM, Brady OJ, Moyes CL, et al. Global distribution and environmental suitability for chikungunya virus, 1952 to 2015. Euro Surveill. 2016;21: pii: 30234. PubMed

4. Centers for Disease Control and Prevention. Chikungunya geographic distribution [cited 2016 Jul 12]. http://www.cdc.gov/ chikungunya/geo/

5. Mouchet J. Aedes aegypti and potential vectors of yellow fever in the Democratic Republic of Somalia and in the French Territory of Afars and Issas [in French]. Bull World Health Organ. 1971:45:383-94.

6. World Health Organization. Rift Valley fever-East Africa, 1997-1998. MMWR Morb Mortal Wkly Rep. 1998;47:261-4.

7. World Health Organization. Outbreaks of Rift Valley fever in Kenya, Somalia and United Republic of Tanzania, December 2006-April 2007. Wkly Epidemiol Rec. 2007;82:169-78.

8. Kanesa-thasan N, Chang GJ, Smoak BL, Magill A, Burrous MJ, Hoke CH Jr. Molecular and epidemiologic analysis of dengue virus isolates from Somalia. Emerg Infect Dis. 1998;4:299-303. http://dx.doi.org/10.3201/eid0402.980220

9. Cardona-Ospina JA, Villamil-Gomez WE, Jimenez-Canizales CE, Castaneda-Hernandez DM, Rodriguez-Morales AJ. Estimating the burden of disease and the economic cost attributable to chikungunya, Colombia, 2014. Trans R Soc Trop Med Hyg. 2015;109:793-802. http://dx.doi.org/10.1093/trstmh/trv094
Address for correspondence: Alessandro Bartoloni, Clinica Malattie Infettive, Dipartimento di Medicina Sperimentale e Clinica, Università Degli Studi di Firenze, Largo Brambilla 3, Florence, Italy; email: alessandro.bartoloni@unifi.it

\section{Meningococcal Disease in US Military Personnel before and after Adoption of Conjugate Vaccine}

\author{
Michael D. Decker \\ Author affiliations: Sanofi Pasteur, Swiftwater, Pennsylvania, \\ USA; Vanderbilt University School of Medicine, Nashville, \\ Tennessee, USA
}

DOI: http://dx.doi.org/10.3201/eid2211.150498

To the Editor: In their recent letter (1), Broderick et al. provided useful information about the remarkable declines in incidence of meningococcal disease among active-duty US military personnel since the early 1970s, when meningococcal vaccination began within that population. The authors reported that the incidence of meningococcal disease from vaccine-covered serogroups was 0.183 cases $/ 100,000$ persons during 2006-2013 among persons vaccinated with quadrivalent conjugate meningococcal vaccine (MCV-4), compared with 0.307 cases/100,000 persons during 2000-2013 among persons vaccinated with quadrivalent polysaccharide meningococcal vaccine (MPSV-4). They stated that, because these rates did not differ significantly, case rates were similar in personnel vaccinated with MCV-4 and MPSV-4. Although statistically correct, this comment might mislead the unwary reader.

The absence of a significant difference does not necessarily mean that the 2 vaccines have similar effectiveness. The incidence rate of meningococcal disease was $68 \%$ higher $([0.307-0.183] \times 100 / 0.183)$ during the period of MPSV-4 use than during the period of MCV-4 use. If the same findings arose in a study of sufficient size to achieve statistical significance, this difference would be considered of substantial clinical importance. A happy consequence of the long-term temporal trends in meningococcal incidence and the success of these vaccines is that the incidence of meningococcal disease is now sufficiently reduced that even the very large active-duty population is too small to provide the statistical power to declare these 2 different incidence rates as being statistically different. 